University of Warwick institutional repository: http://go.warwick.ac.uk/wrap This paper is made available online in accordance with publisher policies. Please scroll down to view the document itself. Please refer to the repository record for this item and our policy information available from the repository home page for further information.

To see the final version of this paper please visit the publisher's website. Access to the published version may require a subscription.

Author(s): B. ELVEVÅG, T. McCORMACK, A. GILBERT, G. D. A. BROWN, D. R. WEINBERGER and T. E. GOLDBERG

Article Title: Duration judgements in patients with schizophrenia Year of publication: 2003

Link to published version: http://dx.doi.org/10.1017/S0033291703008122

Publisher statement: None 


\title{
Duration judgements in patients with schizophrenia
}

\author{
B. ELVEVÅG, ${ }^{1}$ T. MCCORMACK, A. GILBERT, G. D. A. BROWN, \\ D. R. WEINBERGER AND T. E. GOLDBERG \\ From the Clinical Brain Disorders Branch, NIMH/NIH, Bethesda, MD, USA; and Department of Psychology, \\ Warwick University, Coventry
}

\begin{abstract}
Background. The ability to encode time cues underlies many cognitive processes. In the light of schizophrenic patients' compromised cognitive abilities in a variety of domains, it is noteworthy that there are numerous reports of these patients displaying impaired timing abilities. However, the timing intervals that patients have been evaluated on in prior studies vary considerably in magnitude (e.g. $1 \mathrm{~s}, 1 \mathrm{~min}, 1 \mathrm{~h}$ etc.).
\end{abstract}

Method. In order to obviate differences in abilities in chronometric counting and place minimal demands on cognitive processing, we chose tasks that involve making judgements about brief durations of time $(<1 \mathrm{~s})$.

Results. On a temporal generalization task, patients were less accurate than controls at recognizing a standard duration. The performance of patients was also significantly different from controls on a temporal bisection task, in which participants categorized durations as short or long. Although time estimation may be closely intertwined with working memory, patients' working memory as measured by the digit span task did not correlate significantly with their performance on the duration judgement tasks. Moreover, lowered intelligence scores could not completely account for the findings.

Conclusions. We take these results to suggest that patients with schizophrenia are less accurate at estimating brief time periods. These deficits may reflect dysfunction of biopsychological timing processes.

\section{INTRODUCTION}

Distortions in the sense of time have featured prominently in psychoanalytical accounts of psychopathology in general (Hartocollis, 1975) and schizophrenia specifically (Seeman, 1976). Indeed, research on time estimation in schizophrenia has a long history (Clausen, 1950; Lhamon \& Goldstone, 1956; Webster et al. 1962; Lhamon et al. 1965; Orme, 1966; Carlson \& Feinberg, 1968), and there have been numerous reports of impaired temporal comprehension in these patients (Dilling \& Rabin, 1967; Johnson \& Peztel, 1971; Lhamon \& Goldstone,

\footnotetext{
1 Address for correspondence: Dr Brita Elvevåg, Clinical Brain Disorders Branch, NIMH/NIH, Building 10, Rm. 4S235, Bethesda, MD 20892, USA.
}

1973; Densen, 1977; Wahl \& Sieg, 1980; Tysk, 1983a, b, 1984, 1990; Rammsayer, 1990; Tracy et al. 1998; though see Webster et al. 1962; Goldstone et al. 1979; Crain et al. 1975). Studies have indicated that schizophrenic patients are not simply less accurate in time estimation tasks, but show a particular kind of distortion in timing, in that they tend to overestimate time intervals (Tracy et al. 1998; Tysk, $1983 a, b, 1984$, 1990). In an unpublished study, we had participants tap in synchrony with an auditory beat (a metronome at 30 or 60 beats per minute (bpm)) for $5 \mathrm{~min}$. The metronome was then switched off and participants were to continue as before for $5 \mathrm{~min}$, but now were required to generate the rhythm internally. Not surprisingly, when asked to tap without the metronome, 
controls were better able to generate a constant tempo with minimal fluctuations than were patients with schizophrenia. Interestingly, in the 30-bpm task patients disproportionately speeded up their responses over time. Somewhat similar findings have been observed in Parkinson's disease patients who showed shorter inter-response intervals with greater variance (O'Boyle et al. 1996).

On the basis of such studies, a timing deficit in schizophrenia would appear to be well established. These findings of timing disturbances may provide important clues concerning the core cognitive deficits in schizophrenia (Andreasen et al. 1999). However, it is important to consider whether such findings reflect general impairments in cognitive processes rather than a specific difficulty with temporal processing (Rammsayer, 1990, 1999). For example, memory for temporal order has been shown in amnesic patients with Korsakoff's syndrome to be dissociable from item memory (Shimamura et al. 1990). However, we found that, although memory for temporal order was compromised in patients with schizophrenia, this deficit was highly correlated with generally poorer item memory (i.e. recall; Elvevåg et al. 2000). This difficulty of dissociating problems in time estimation from those in memory dysfunction is found also in the neurological literature (e.g. Williams et al. 1989; Mimura et al. 2000).

Moreover, a number of studies of human timing (Fortin et al. 1993; Zakay \& Block, 1996, 1997; Fortin, 1999) have indicated that accurate estimation of intervals in the order of several seconds requires sustained focusing of attention, and furthermore strategies such as counting can be recruited in making such judgements. The involvement of attentional and strategic processes in these tasks is also potentially problematical, given the well-documented attentional impairments in patients with schizophrenia (e.g. Nuechterlein \& Dawson, 1984; Cornblatt et al. 1989; Cornblatt \& Keilp, 1994), along with working memory deficits (e.g. Elliot et al. 1995, 1998; Park et al. 1995; Fleming et al. 1997; Stone et al. 1998). Researchers who have conducted studies of time estimation in schizophrenia are well aware of the role of counting strategies in performing such tasks: Tysk (1983a) has interpreted his results as indicating that patients with schizophrenia 'tend to count seconds too fast' (p. 913; see also Lhamon \& Goldstone, 1956), although we contend that this interpretation is rather unlikely since patients' rate of articulation is likely to be somewhat slower, in the context of general slowing on tests of speed and reaction time (King, 1976). Although it is sometimes explicitly assumed that the rate of counting directly reflects the operation of an internal clock (see Pastor et al. 1992), it seems highly likely that the rate of counting will be affected by other factors. Thus, while Tysk may be correct that patients with schizophrenia differ from controls in the nature of their counting, and are impaired on some time estimation tasks, it is difficult to conclude that this impairment reflects deficits in basic timing mechanisms.

Although many of the reported deficits in timing in schizophrenia may be explicable in terms of impairments in other cognitive processes, there are nevertheless reasons to believe that primitive timing mechanisms are also impaired in this population. Rammsayer (1990) has shown that patients with schizophrenia perform worse than controls on a task that requires discrimination of very brief durations (in the order of $50-100 \mathrm{~ms}$ ), a task that is perceptual in nature and places minimal demands on non-temporal processes. In addition, extensive research on animal and human timing has suggested that timing mechanisms are affected by the functioning of dopamine (Maricq et al. 1981; Maricq \& Church, 1983; Church, 1984; Meck, 1986, 1996; Rammsayer, 1989, 1993, 1997, 1999; Rammsayer \& Gallhofer, 1995; Harrington \& Haaland, 1998), a neurochemical system that is implicated in schizophrenia (for a review see Carlsson et al. 1999). Moreover, there is considerable debate regarding the role of the cerebellum in representing temporal information (for a review see Ivry, 1997). The dysfunction of timing mechanisms in schizophrenia is therefore further complicated by the fact that these patients have been shown to have cerebellar pathology (for a review see Martin \& Albers, 1995) and 'cognitive dysmetria' due to postulated dysfunctional prefrontalthalamic-cerebellar circuitry (Andreasen et al. 1996).

In the current study we sought to examine the timing problem in schizophrenia while attempting to minimize the role of confounding cognitive processes and focus more directly on 
timing mechanisms by employing brief stimuli so that the use of certain strategies, such as counting, would be reduced or eliminated. The current research focuses on examination of what processes may be impaired in time estimation over short time scales. This information may then shed light on how these faulty processes give rise to the cognitive deficits at the level assessed in standard psychological assessments. The aim of the current study was to examine whether timing was impaired in schizophrenia by examining performance on two tasks that are generally agreed to measure the functioning of certain timing mechanisms directly, and which place a limited demand on other cognitive processes. These tasks are temporal generalization (Wearden, 1992; Wearden \& Towse, 1994; Wearden et al. 1997a) and temporal bisection (Allan \& Gibbon, 1991; Wearden, 1991b; Wearden \& Ferrara, 1995, 1996; Nichelli et al. 1996; Penney et al. 1998) which are analogues of animal timing tasks (Church \& Deluty, 1977; Church \& Gibbon, 1982). Although, these tasks only measure certain aspects of timing behaviour, they offer a number of advantages for comparing clinical populations with controls. The tasks involve simple comparative judgements about durations and thus are easy to explain to participants. The stimulus durations that are employed are short enough (typically less than $1 \mathrm{~s}$ ) to prevent chronometric counting (although longer durations can be used if counting is suppressed; Wearden et al. 1997a). Furthermore, the bisection task has been used successfully to demonstrate deficits in timing of short intervals in patients with cerebellar degeneration or frontal damage (Nichelli et al. 1995, 1996). A further advantage of these tasks is that mathematical models that assume that performance is based directly on internal clock processes provide extremely good accounts of the data generated from them under a wide variety of experimental conditions (Allan \& Gibbon, 1991; Wearden, 1991; Wearden \& Ferrara, 1995, 1996; Wearden et al. 1997b; Penney et al. 1998) in healthy individuals. Most of these formal models fall within the general framework of Scalar Expectancy Theory (Gibbon, 1977; Gibbon et al. 1984), which is a successful and widely applied theory of timing, accounting for a broad range of animal and human data.
Table 1. Background scores for the control participants and patients

\begin{tabular}{|c|c|c|c|c|}
\hline \multirow[b]{2}{*}{ Measure } & \multicolumn{2}{|c|}{ Controls } & \multicolumn{2}{|c|}{ Patients } \\
\hline & Mean & (s.D.) & Mean & (S.D.) \\
\hline Age (years) & $29 \cdot 43$ & $(11 \cdot 50)$ & $32 \cdot 80$ & $(8 \cdot 39)$ \\
\hline WRAT-R IQ** & $112 \cdot 48$ & $(9 \cdot 32)$ & $102 \cdot 63$ & $(13 \cdot 28)$ \\
\hline WAIS-R IQ** & $118 \cdot 23$ & $(20 \cdot 81)$ & $91 \cdot 24$ & $(18 \cdot 87)$ \\
\hline Cattell IQ** & $109 \cdot 39$ & $(12 \cdot 56)$ & $88 \cdot 59$ & $(13 \cdot 06)$ \\
\hline
\end{tabular}

\section{METHOD}

\section{Participants}

Nineteen in- or out-patients (15 male and four female) from the National Institute of Mental Health participated in this study. All patients fulfilled DSM-IV criteria for schizophrenia, as determined by the Structured Clinical Interview for DSM-IV (SCID) with three psychiatrists reaching a consensus diagnosis. Patients generally had multiple hospital admissions due to incomplete responses to conventional treatments. All of the patients were receiving atypical neuroleptic medication at the time of the study (11 on clozapine or olanzapine, seven on risperidone and one on quentiapine) and two were also receiving typical neuroleptic medication (fluphenazine). Four patients also received anticholinergic medication, and 16 were on adjunctive medication. Twenty-three normal healthy control volunteers (six males and 17 females) were recruited through the National Institutes of Health volunteer panel. Out-patients and control volunteers were paid for their participation.

No participant (control or patient) had a history of traumatic brain injury, epilepsy, developmental disorder, diagnosable current substance dependence, or known neurological condition. All participants had normal or normal corrected vision. The internal review board at the National Institute of Mental Health approved this study and informed consent was obtained from all participants prior to testing.

Table 1 shows the mean ages and background test scores of the patients and controls. Three baseline tests were used to index intellectual function. The first was a test of reading proficiency - the Wide Range Achievement Test-Reading (WRAT-R) (Jastak \& Wilkinson, 1984), which is widely used as a putative 
measure of pre-morbid intellectual functioning (Wiens et al. 1993; Goldberg et al. 1995; Kremen et al. 1996). The second was a standard test of current non-verbal or fluid intelligence: Cattell's Culture Fair Intelligence Test (Cattell, 1971; Institute for Personality and Ability Testing, 1973), Scale 2, Form A. The test involves timed non-verbal problem-solving. Participants were also evaluated on a short version of the Wechsler Adult Intelligence Scale (WAIS-R) (Wechsler, 1981; see also Kaufman, 1990; Missar et al. 1994). The substantial drop in intelligence from estimated pre-morbid function is often reported in schizophrenia (Weickert et al. 2000). Significant differences were revealed by $t$ tests (in all cases, $P<0.01$ ) between the groups in terms of scores on the WRAT-R, Cattell Culture Fair Intelligence Test and WAIS-R. There was no significant group difference in age $(P>0 \cdot 1)$. Patients' digit span (forwards and backwards) was also assessed (Wechsler Memory ScaleRevised, Wechsler, 1987), and their average raw combined span was $13 \cdot 8$ (out of 24 ; S.D. $=4 \cdot 1$ ).

\section{Apparatus and stimuli}

An Apple Macintosh computer running Cedrus Superlab software controlled stimulus generation for Experiments 1 and 2. The auditory stimuli were $500 \mathrm{~Hz}$ tones produced by the computer's speaker, and the visual displays were presented on a black-and-white screen. All participants were tested individually, and gave verbal responses.

\section{EXPERIMENT 1: TEMPORAL GENERALIZATION}

In the temporal generalization task, participants were initially presented with a standard duration tone $(500 \mathrm{~ms})$, and at the test phase they judged whether presented stimuli of various durations (125, 250, 375, 625, 750 and $875 \mathrm{~ms})$ were or were not the standard. Plots of the proportions of positive responses to standard and non-standard test stimuli yield characteristic generalization gradients, with the probability of giving an erroneous positive response to a non-standard stimulus declining with its 'distance' from the standard (Wearden, 1992; Wearden et al. $1997 a, b)$. The index of accuracy of time estimation on this task is the steepness of such generalization gradients, with previous studies showing that young children and elderly adults will produce relatively flat gradients (i.e. greater numbers of erroneous positive responses to non-standard stimuli relative to the number of correct positive responses to standard stimuli; McCormack et al. 1999; Wearden et al. 1997 b).

When plotted on a linear scale, such gradients are normally asymmetrical, with positive responses more likely to stimuli that are longer than the standard than to those shorter than the standard but of equal distance away (Wearden, 1992; although this is not always true for animal performance on temporal generalization tasks, Church \& Gibbon, 1982). For example, if the standard were $500 \mathrm{~ms}$, more erroneous positive responses are normally given to a $625 \mathrm{~ms}$ stimulus than a $375 \mathrm{~ms}$ stimulus. This asymmetry reflects a basic property of human timing (Wearden, 1993). However, the extent to which gradients are asymmetrical in this way in any given study also reflects the veridicality of longterm memory of the standard. Previous research suggests that the representation of the time intervals may become distorted in long-term memory (Meck \& Church, 1987 a; Meck et al. 1987; Shurtleff et al. 1992), with the standard being systematically mis-remembered as being either shorter (McCormack et al. 1999) or longer (Wearden et al. 1999; McCormack et al. 2002) than it actually was. Since responses are made by comparing the memory representation of the standard with the representation of the current test stimulus, such distortion will affect the probability that erroneous positive responses are given to stimuli shorter or longer than the standard. Thus, the degree of asymmetry of the generalization gradient will in part depend on the extent to which such distortion occurs.

The present study compared performance of schizophrenic patients and controls on such a task. In particular, we were interested in whether the patients would produce flatter gradients than controls, indicating less accurate interval timing, and whether the degree of asymmetry of their gradients would differ, indicating impaired or distorted memory for durations.

\section{Procedure}

Participants were seated in a quiet room in front of a computer monitor. A version of the generalization task was used that had been designed for participants who may find it difficult to 


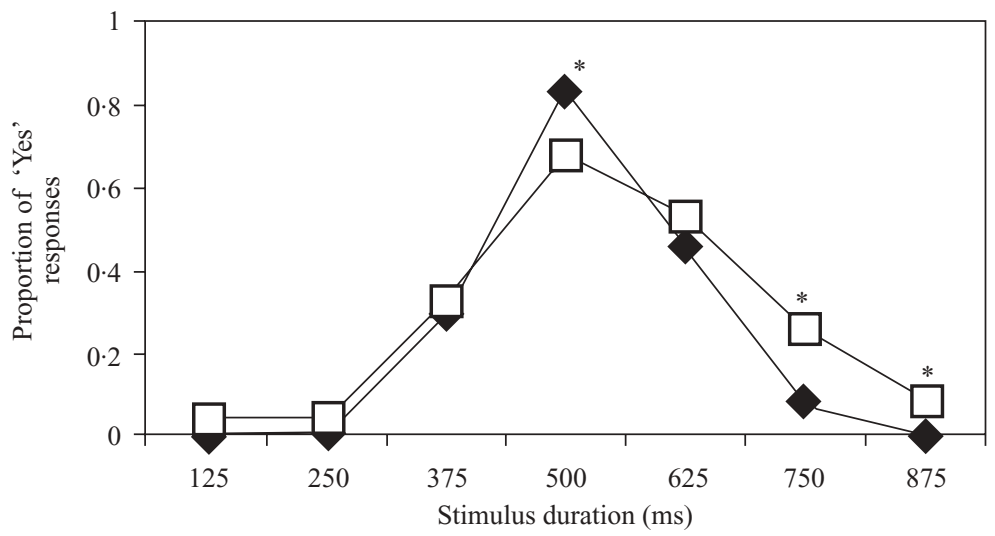

FIG. 1. Proportion of 'Yes' responses as a function of stimulus duration for schizophrenic patients ( $\square$ ) and control participants ) in the temporal generalization task (Experiment 1$)$. ( ${ }^{*}$ Group difference significant in post hoc $t$ tests.)

understand abstract computerized tasks (such as children or very elderly adults; McCormack et al. 1999). Rather than instructing participants to identify a standard, the stimulus identification task was set in an easily comprehensible context. Participants heard a tone $500 \mathrm{~ms}$ in length while viewing a picture of an owl on a computer screen, and they were told it was 'the sound made by the owl'. Participants were told that the owl's sound was always the same pitch and was always of the same duration, and then were presented with the owl's sound four more times. Participants then had four demonstration trials in which they heard tones of length 500, 750,500 and $250 \mathrm{~ms}$. After each tone was played, they were told whether the tone was or was not the owl's sound, and it was then explained to participants that their task was to judge whether other sounds were or were not the owl's sound. Participants then had five practice trials: one of the practice trials was the $500 \mathrm{~ms}$ tone and one each of the other test stimuli that had not been previously played $(125,375,625$ and $875 \mathrm{~ms})$. Participants were given feedback as to whether their responses were correct or not. Testing immediately followed the last practice trial, with test stimuli presented in eight blocks of eight trials (64 trials in total). Each block included one presentation of each nonstandard tone (e.g. 125, 250, 375, 625, 750 and $875 \mathrm{~ms}$ ) and two presentations of the standard 'owl' tone of $500 \mathrm{~ms}$. Participants were assigned to one of two versions of the task, with the order in which the stimuli were presented in each block reversed between versions. Responses were given verbally, and were recorded by the experimenter. As in the practice trials, feedback was given after each response.

\section{Results}

Accuracy was first examined as overall 'yes' responses across tone length. An analysis of variance (ANOVA) was conducted on these data with diagnostic group (controls and patients) as a between-subjects factor and tone-length as the within-subjects factor $(125,250,375,500$, 625,750 and $875 \mathrm{~ms}$ ). The main effect of group failed to reach significance though a trend was present, $F(1,40)=3 \cdot 57$, mean S.E. $=0 \cdot 038, P=$ $0 \cdot 07$, but there was a significant effect of tonelength, $F(6,240)=134 \cdot 64$, mean S.E. $=0 \cdot 024$, $P<0.01$, and, importantly, there was a significant interaction between group and tone-length, $F(6,240)=4 \cdot 293$, mean s.E. $=0.024, \quad P=0.01$ (see Fig. 1).

Post hoc $t$ tests were calculated to compare the groups at the different stimulus durations, correcting for multiple tests of comparison using a modified Bonferroni method (Holm's (1979) sequentially rejective procedure). These revealed that the patients made significantly more erroneous positive responses to the 750 and $875 \mathrm{~ms}$ stimuli, and significantly fewer correct positive responses to the $500 \mathrm{~ms}$ stimulus than did controls.

In order to ascertain whether these results might be attributable to a decay of the standard in general, we compared performance on the 
first half of the experiment with the second half by calculating ANOVAs separately for patients and controls. Although such an analysis cannot totally eliminate the possibility of memory decay operating during the task, the fact that there was not a significant effect of time in either group (in both cases, $P>0 \cdot 1$ ) thus does not provide support for the idea of a general mnemonic failure (i.e. forgetting) over time.

Further analyses examined the shape of the generalization gradients in more detail. Inspection of the gradients (see Fig. 1) suggests that both groups showed the usual asymmetry, with more positive responses to stimuli longer than the standard than to those shorter than the standard but of equal distance from it. This asymmetry appears to be more marked in the gradient of the group of patients. Asymmetry was tested by separate comparisons of the proportions of positive responses to each of the three pairs of durations of equal distance from the standard. There was insufficient variance in the data to compare the 125 and the $875 \mathrm{~ms}$ stimuli. However, both groups produced significantly more positive responses to the 750 than the 250 ms stimulus $(F(1,22)=9 \cdot 16$, mean s.E. $=$ $0.006, \quad P<0.01$ for controls; $F(1,18)=17 \cdot 3$, mean S.E. $=0.026, P<0.01$ for the group of patients), with the patients, but not the controls, also producing significantly more positive responses to the 625 than the $375 \mathrm{~ms}$ stimulus $(F(1,18)=4.47$, mean s.E. $=0.083, \quad P<0.05)$. Thus, asymmetry was significant to some extent for both groups, and extended to more stimulus pairs for patients than the controls.

Since the groups differed significantly on all three measures of IQ, subsequent analyses addressed the possibility that the significant interaction between group and tone length might be a result of such differences. An analysis of covariance (ANCOVA) with a between-subjects factor of group, a within-subjects factor of tone length, and three covariates of WAIS-R, WRAT-R and Cattell scores was carried out, with four participants excluded from the analysis for whom scores on one or more of the IQ measures were not available. Inspection of the epsilon values, to check the assumption of homogeneity of variance, showed that there was a high degree of departure from the sphericity assumption (Greenhouse-Geisser $\varepsilon=0 \cdot 39$ ); we therefore report the results of the corresponding multivariate analysis. When WAIS-R, WRAT$\mathrm{R}$, and Cattell scores were covaried in this way, the interaction between group and tone length was near significance $(F(6,28)=2 \cdot 33, P=0 \cdot 06)$. This suggests that group differences in IQ contributed to group differences in performance to some degree, although the fact that the interaction remained marginally significant when all three IQ measures were taken into account indicates that the results cannot be completely explained in this way. Moreover, correlating patients' forwards and backwards digit span with a single measure of the proportion correct (the number of 'yes' responses to the $500 \mathrm{~ms}$ stimulus divided by the total number of 'yes' responses) did not reveal a significant correlation $(r(19)=-0 \cdot 161, P>0.5$ for forward digit span; $r(19)=0 \cdot 241, P>0 \cdot 1$ for backward span), a finding we take to suggest that working memory alone (as measured by the digit span task) cannot sufficiently explain the results from Experiment 1.

\section{EXPERIMENT 2: TEMPORAL BISECTION}

In the temporal bisection task, there were two standards, one long and one short, and participants judged whether test stimuli were more similar to the long or to the short standard. Like the generalization task, the bisection task is based on a paradigm originally used to study animal timing (Church \& Deluty, 1977; Maricq et al. 1981), which has been successfully adapted for use with humans (Allan \& Gibbon, 1991; Wearden, 1991; Nichelli et al. 1995, 1996; Wearden \& Ferrara, 1995, 1996; McCormack et al. 1999; Droit-Volet \& Wearden, 2003). Data from this task are normally plotted as S-shaped bisection curves, in which the proportion of 'long' responses is plotted as a function of stimulus duration. Performance is indicated by the steepness of this function, with the bisection curves of patients with frontal damage (Nichelli et al. 1995), and patients with cerebellar degeneration (Nichelli et al. 1996) being less steep than those of healthy adults (at least over some ranges of intervals).

Another aspect of this function that is usually analysed is the bisection point. This is the hypothetical duration at which responses would be equally divided between long and short. In human timing, this point is normally located 


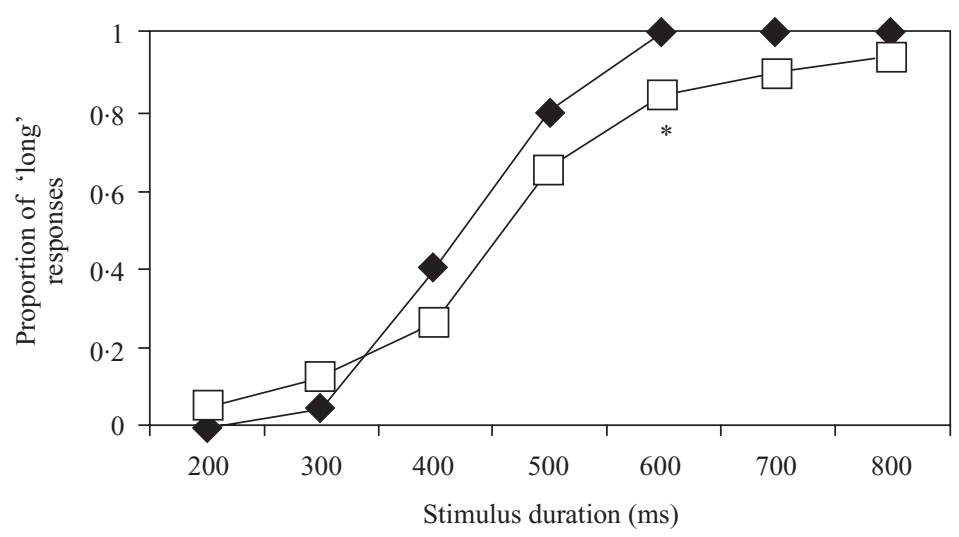

FIG. 2. Proportion of 'long' responses as a function of stimulus duration for schizophrenic patients $(\square)$ and control participants

$\checkmark)$ in the temporal bisection task (Experiment 2). (*Group difference significant in post hoc $t$ tests.)

between the arithmetic and the geometric means of the two standard durations, although it is often closer to the arithmetic mean when the ratio of the short to long standards is large (see Allan \& Gibbon, 1991). ${ }^{1} \uparrow$ The formal measure of steepness of the bisection gradients is the Weber ratio. This is calculated using the bisection point and difference limen. The bisection point is the hypothetical duration at which $50 \%$ of responses are classified as 'long', and the difference limen is half the difference between the hypothetical durations at which $25 \%$ and $75 \%$ of responses are long. Thus, the Weber ratio is calculated by dividing the difference limen by the bisection point. The Weber ratio provides a measure of a participant's precision and ability to discriminate specific stimuli that is independent of the actual values of the physical stimuli.

We compared performance of schizophrenic patients and controls on this temporal bisection task. On the basis of the findings of Experiment 1, we predicted that patients would produce flatter gradients than controls, indicating less accurate interval timing.

\section{Procedure}

Participants were seated in a quiet room in front of a computer monitor. As in Experiment 1, the task was set in a context designed to make it easy for participants to understand. A computer

\footnotetext{
$\dagger$ The notes will be found on page 1259 .
}

monitor displayed two birds, a big one and a small one. Participants were told that the two birds made sounds of different lengths and that the big bird made a long sound and the small bird made a short sound. Participants then heard examples of the short (200 ms) and long (800 ms) sound while the appropriate picture was shown on the screen. There were five alternating presentations of each of the sounds. Participants then had seven practice trials (one example of each of the stimuli: 200, 300, 400, $500,600,700$ and $800 \mathrm{~ms}$ ) during which they heard a tone and had to state whether it was more like the big bird's or the small bird's sound. No feedback was given as to participants' accuracy. After the practice trials, participants completed five blocks of seven trials, with each block containing one presentation of each stimulus (35 trials in total). The experimenter recorded the responses given ('small bird' or 'big bird'). As in Experiment 1, participants were assigned to one of two versions of the task, with the order of stimulus presentations within each block reversed between versions.

\section{Results}

Fig. 2 shows the bisection curves for the two groups. Performance was first examined as the overall proportion of 'long' responses across tone length. An analysis of variance was conducted on these data with diagnostic group (controls and patients) as a between-subjects 
factor and tone-length as the within-subjects factor $(200,300,400,500,600,700$ and $800 \mathrm{~ms})$. There was a main effect of group, $F(1,40)=$ $5 \cdot 10$, mean s.E. $=0 \cdot 066, P<0 \cdot 03$, with the control group producing more 'long' responses than the patient group, and a significant effect of tone-length, $F(6,240)=239.63$, mean s.E. $=$ $0.030, P<0.01$, and importantly there was a significant interaction between group and tonelength, $F(6,240)=3 \cdot 34$, mean s.E. $=0 \cdot 030, P<$ $0 \cdot 01$.

Post hoc $t$ tests, corrected as before for multiple tests of comparison (Holm's (1979) sequentially rejective procedure), which compared the groups at the different stimulus durations revealed a significant group difference on the 600 ms stimulus only.

As in the analysis of the data from Experiment 1 , we examined whether the significant interaction between group and tone length might be a result of group differences in IQ. An analysis of covariance (ANCOVA) with a between-subjects factor of group, a within-subjects factor of tone length, and three covariates of WAIS-R, WRAT-R, and Cattell scores was carried out, with four participants excluded from the analysis for whom scores on one or more of the IQ measures were not available. However, checking the assumption of homogeneity of variance by inspecting the epsilon values showed that there was a high degree of departure from the sphericity assumption (Greenhouse-Geisser $\varepsilon=0.47$ ); therefore, we report the results of the corresponding multivariate analysis. When WAIS-R, WRAT-R, and Cattell scores were covaried out in this way, the interaction between group and tone length remained significant $(F(6,28)=2.53, \quad P<0.05)$. Thus, group differences in IQ cannot explain the effect of group on performance. Moreover, correlating patients' forwards and backwards digit span separately with the Weber ratio (see below) did not reveal significant correlations $(r(17)=$ $-0 \cdot 247, P>0 \cdot 1$ for forward digit span; $r(17)=$ $-0.037, P>0.1$ for backward digit span) a finding we take to suggest that working memory alone (as measured by the digit span task) cannot sufficiently explain the results from the temporal bisection task.

In order to calculate the values of the difference limen and bisection point every participant's bisection curve was modelled using the following equation:

$$
P\left(\operatorname{long} \mid D_{i}\right)=\frac{1}{1+e^{-s .\left(D_{i}-\text { mean }\right)}},
$$

where $P\left(\operatorname{long} \mid D_{i}\right)$ is the probability of responding 'long' to a given test stimulus $D_{i}, s$ is the slope of the S-shaped curve and mean is the Bisection Point. For each participant $s$ and mean were estimated separately. The median $\mathrm{R}^{2}$ value obtained was 0.99 for the controls, and 0.98 for the 17 patients we included.

The mean difference limen of the group of patients was $27 \cdot 28$, and that of the control group was $57 \cdot 17 .^{2}$ An ANOVA found that there was a significant difference between the groups in the size of the difference limen, $F(1,38)=6 \cdot 17$, mean S.E. $=1416.00, P<0.02$. Inspection of the bisection gradients (Fig. 2) suggests that the bisection points for the two groups are somewhere between the arithmetic $(500 \mathrm{~ms})$ and the geometric $(400 \mathrm{~ms})$ mean. The mean bisection point was $431.74 \mathrm{~ms}$ for the control group and $481.59 \mathrm{~ms}$ for the patients. An ANOVA found a significant difference between the groups in the value of the bisection point, $F(1,38)=7 \cdot 04$, mean S.E. $=3450 \cdot 70, P<0 \cdot 02$.

The difference limen and the bisection point were used to calculate the Weber ratio. The mean Weber ratio of the control group was found to be 0.064 , and that of the patient group was $0 \cdot 12$. An ANOVA found a marginally significant difference between the groups, $F(1,38)=4.04$, mean s.E. $=0.007, P=0.052$ in the value of the Weber ratio. Although the steepness of the curves is different between the groups, as shown by the significant group effect on the difference limen, the difference between them is only marginally significant when steepness is adjusted to take into account the bisection point.

\section{DISCUSSION}

In both Experiments 1 and 2, the performance of patients with schizophrenia differed from that of healthy adults on tasks that involved making judgements about the durations of brief auditory stimuli. Our results indicate that timing is impaired in patients even when the tasks involve judgements about very short durations (see also Rammsayer, 1990). Importantly, these 
impairments could not be explained fully in terms of group differences in estimated premorbid or current intelligence or patients' poor working memory ability (as measured by digit $\operatorname{span}^{3}$ ). In Experiment 1, patients' generalization gradient was less steep than that of controls. Although there were significant group differences in performance on the temporal bisection task, the difference in the Weber ratio between groups was only marginally significant. The fact that group differences were more pronounced on the generalization task, notwithstanding the provision of feedback in Experiment 1 but not 2 , is consistent with findings of previous studies that have indicated that the generalization task is a more sensitive task than the bisection task (Wearden et al. $1997 a, b$ ).

In addition to group differences in overall levels of performance, some features of the data suggested that there may be qualitative differences between timing in patients and controls. In Experiment 1, the generalization gradient was more markedly asymmetrical in patients than in controls. Furthermore, in Experiment 2, the bisection point was larger for patients than for controls. These effects can be addressed within the framework of Scalar Expectancy Theory. Formal models of timing assume two separate mnemonic components are involved in the tasks in Experiments 1 and 2. Long-term memory holds the standard, and working memory is used to compare the test durations with the retrieved representation of the standard from long-term memory. If the representation of a standard duration in long-term memory is systematically distorted (e.g. remembered as longer than it really is) effects akin to those observed here may be obtained. For example, McCormack et al. (1999) attributed qualitative differences in children's temporal generalization to memory distortion. If the standards are remembered by patients as longer than they truly are, the two key effects reported above may be explained. Greater asymmetric generalization (Experiment 1) could result because a given test duration that is longer than the true standard will be closer to the distorted memory of the standard. In the bisection experiment, a proportional distortion (e.g. a $10 \%$ increase) of memory of both the short and the long standards will lead to a mid-range stimulus becoming relatively closer to the remembered short standard than to the remembered long standard. However, it should be noted that alternative explanations may be possible. For example, greater asymmetry in temporal generalization tasks is often associated with lower overall levels of performance (Wearden et al. $1997 a, b$; McCormack et al. 1999), and rightward shifts in bisection point could result from a simple bias against responding long.

We note that not all timing deficits in schizophrenia can be explained by reference to distorted standards. Indeed, Rammsayer's (1990) findings would suggest that patients with schizophrenia are impaired on tasks that do not have a long-term memory component, implicating clock processes. Further research explicitly addressed at partitioning variability in performance to perceptual versus memory processes is necessary to resolve this issue.

Unlike Rammsayer's (1990) study of timing of brief intervals in schizophrenia, the current tasks have a long-term memory component (since the standard is assumed to be held in long-term or reference memory), a component that appears not to be involved in temporal discrimination of extremely brief intervals (Rammsayer, 1999). It is not clear to what extent either of the memory components in formal models derived from Scalar Expectancy theory can be identified with the types of memory measured by standard memory tasks (but see Fortin, 1999 for an alternative view). However, in the light of the absence of a general mnemonic failure over time or a significant correlation with a working memory measure such as digit span, we suggest that simply explaining the findings in terms of working memory would be insufficient. Indeed, the type of memory distortion that might underlie our findings is generally considered to be a long-term memory factor rather than a working memory one (although we acknowledge the current major research effort to develop a variety of techniques with which to disentangle working memory from long-term memory, from short-term memory and from controlled attentional processes - see Engle et al. 1999).

Attempting to separate differences between specific deficits and generalized deficits (as in the current study) is a major issue in cognitive research in patients with schizophrenia, especially those with chronic courses. Indeed, it 
is important to establish whether patients' performance reflects the illness itself or whether it is attributable to the difficulty level of the tasks (Chapman \& Chapman, 1978). We have preliminary evidence for patients demonstrating an impairment in stimulus identification when the stimuli are tones of varying durations, but not when the stimuli are lines of varying lengths. Importantly, task difficulty issues alone could not account for these new data since the line length judgement task did not seem to be an easier task given the large number of errors made by both groups. We regard this as evidence that patients do not have a global problem with stimulus identification, and thus take our findings to support the notion of a specific impairment in timing abilities in patients with schizophrenia.

On the basis of the current findings and those of numerous previous studies, schizophrenic patients appear to have deficits in timing in a very wide range of time intervals from $<100 \mathrm{~ms}$ (Rammsayer, 1990), <1 s (the current study) through to intervals in the order of seconds (Tracy et al. 1998) and many minutes (Tysk, 1983a). An unresolved, but important, issue in timing research is whether there are separable clock systems for these different interval ranges. A considerable body of research links clock processes with the basal ganglia (Meck, 1986; Artieda et al. 1992; Pastor et al. 1992; Harrington \& Haaland, 1998; Harrington et al. $1998 a$ ), although Ivry and colleagues (Ivry \& Keele, 1989; Ivry, 1993; Clarke et al. 1996) have argued that the cerebellum is heavily implicated not only in motor timing but in at least some kinds of temporal duration judgements. Other neuroanatomical areas are associated with the memory and decision processes in the timing system (Nichelli et al. 1993, 1995; Shaw \& Aggleton, 1994). Given that time perception relies on a variety of hierarchically organized structures and processes it is not surprising that the underlying cortical networks are vast (e.g. right hemisphere prefrontal-inferior parietal network; Harrington et al. 1998 b). Moreover, it seems likely that attention and working memory contribute to temporal perception. Thus, given that schizophrenia may be considered to be a disorder of connectivity (Weinberger et al. 1992; Fletcher et al. 1999; Tononi \& Edelman, 2000), including problems in attention and working memory, the challenge to fractionate the way in which the dynamic network of cortical and subcortical activation contributes to the function and dysfunction of the different components of time perception is clearly important (see Volz et al. 2001).

This issue is further complicated by the involvement of the dopaminergic and cholinergic systems in timing, suggested by reports of deficits in both motor timing and time estimation or perception in Parkinson's disease (for reviews, see Gibbon et al. 1997; Harrington \& Haaland, 1998; but see Ivry \& Keele, 1989), and from research with animals and humans who have been administered dopamine antagonists (Meck, 1986, 1996; Rammsayer, 1993, 1999) or agonists (Stubbs \& Thomas, 1974; Rapp \& Robbins, 1976; Rammsayer, 1990; Rammsayer \& Vogel, 1992), or choline modulators (Meck \& Church, $1987 b$; for a review see Meck, 1996). Regarding the issue of whether the observed impairments in duration judgements of the patients with schizophrenia are side-effects of neuroleptic medication, evidence from previous studies is mixed (Lhamon \& Goldstone, 1956; Goldstone et al. 1979; Tysk, 1983 a; Tracy et al. 1998) with different neuroleptics exerting different effects on timing tasks (Meck, 1986; Rammsayer, 1990, 1997; Rammsayer \& Gallhofer, 1995). It is possible that the use of a psychiatric control group (especially unmedicated) could have helped clarify the particular relevance of time judgement deviations in schizophrenia. The patients in the current study were on neuroleptics and the effects on timing of many of the specific drugs that the patients were taking have not been explored. Specifically, the consequences of patients with schizophrenia who are on drugs that manipulate dopaminergic and cholinergic systems warrants examination, in a patient sample in which this is possible, and in which there is the statistical power to evaluate the effect of cholinergic modulation on the timekeeper in patients with schizophrenia. Clearly, further research is necessary to establish if such medication does contribute to the timing deficit in schizophrenia.

Gordon D. A. Brown and Teresa McCormack were supported by grant 88/S15050 from BBSRC (UK) and grant R000239002 from ESRC (UK). Gordon 
D. A. Brown was also supported by grant R000239351 from ESRC (UK).

\section{NOTES}

1 The geometric mean is the square root of the product of the standards.

${ }^{2}$ Data from two participants (both patients) were excluded from analysis. There was one participant for whom no clear bisection point could be determined, and there was a further participant who had a bisection point which was more than two standard deviations away from the group mean.

${ }^{3}$ We note that digit span is only one of many measures of working memory, and that other measures are likely to be important as well.

\section{REFERENCES}

Allan, G. A. \& Gibbon, J. (1991). Human bisection at the geometric mean. Learning and Motivation 22, 39-58.

Andreasen, N. C., O'Leary, D. S., Cizadlo, T., Arndt, S, Rezai, K., Boles Ponto, L. L., Watkins, G. L. \& Hichwa, R. D. (1996). Schizophrenia and cognitive dysmetria: a positron-emission tomography study of dysfunctional prefrontal-thalamic-cerebellar circuitry. Proceedings of the National Academy of Science, USA 93, 9985-9990.

Andreasen, N. C., Nopoulos, P., O'Leary, D. S., Miller, D. D., Wassink, T. \& Flaum, M. (1999). Defining the phenotype of schizophrenia: cognitive dysmetria and its neural mechanisms. Biological Psychiatry 46, 908-920.

Artieda, J., Pastor, M. A., Lacruz, F. \& Obeso, J. A. (1992). Temporal discrimination is abnormal in Parkinson's disease. Brain 115, 199-210.

Carlson, V. R. \& Feinberg, I. (1968). Individual variations in time judgement and the concept of an internal clock. Journal of Experimental Psychology 77, 631-640.

Carlsson, A., Waters, N. \& Carlsson, M. L. (1999). Neurotransmitter interactions in schizophrenia-therapeutic implications. Biological Psychiatry 46, 1388-1395.

Cattell, R. B. (1971). Abilities: Their Structure, Growth and Action. Houghton-Mifflin: Boston.

Chapman, L. J. \& Chapman, J. P. (1978). The measurement of differential deficit. Journal of Psychiatry Research 14, 303-311.

Church, R. M. (1984). Properties of the internal clock. In Timing and Time Perception (ed. J. Gibbon and L. G. Allan), pp. 566-582. New York Academy of Sciences: New York.

Church, R. M. \& Deluty, M. Z. (1977). Bisection of temporal intervals. Journal of Experimental Psychology: Animal Behavioral Processes 3, 216-228.

Church, R. M. \& Gibbon, J. (1982). Temporal generalization. Journal of Experimental Psychology: Animal Behavior Processes 8, $165-185$.

Clarke, S., Ivry, R., Grinband, J., Roberts, S. \& Shimizu, N. (1996). Exploring the domain of cerebellar timing systems. In Time, Internal Clocks, and Movement (ed. M. A. Pastor and J. Artieda), pp. 257-280. Elsevier Science: Amsterdam.

Clausen, J. (1950). An evaluation of experimental methods of time judgment. Journal of Experimental Psychology 40, 756-761.

Cornblatt, B. A. \& Keilp, J. G. (1994). Impaired attention, genetics, and the pathophysiology of schizophrenia. Schizophrenia Bulletin 20, 31-46.

Cornblatt, B. A., Lenzenweger, M. F. \& Erlenmeyer-Kimling, L. (1989). The Continuous Performance Test, Identical Pairs Version: II. Contrasting attentional profile in schizophrenic and depressed patients. Psychiatry Research 29, 65-85.
Crain, P., Goldstone, S. \& Lhamon, W. T. (1975). Temporal information processing and psychopathology. Perceptual and Motor Skills 41, 219-224.

Densen, M. E. (1977). Time perception and schizophrenia. Perceptual and Motor Skills 44, 436-438.

Dilling, C. A. \& Rabin, A. I. (1967). Temporal experience in depressive states and schizophrenia. Journal of Consulting Psycholology 31, 604-608.

Droit-Volet, S. \& Wearden, J. H. (2003). Temporal bisection in children. Journal of Experimental Child Psychology.

Elliot, R., McKenna, P. J., Robbins, T. W. \& Sahakian, B. J. (1995). Neuropsychological evidence for fronto-striatal dysfunction in schizophrenia. Psychological Medicine 25, 619-630.

Elliot, R., McKenna, P. J., Robbins, T. W. \& Sahakian, B. J. (1998). Specific neuropsychological deficits in schizophrenic patients with preserved intellectual function. Cognitive Neuropsychology $\mathbf{3}$, 45-70.

Elvevåg, B., Egan, M. F. \& Goldberg, T. E. (2000). Memory for temporal order in patients with schizophrenia. Schizophrenia Research 46, 187-193.

Engle, R. W., Kane, M. J. \& Tuholski, S. W. (1999). Individual differences in working memory capacity and what they tell us about controlled attention, general fluid intelligence, and functions of the prefrontal cortex. In Models of Working Memory: Mechanisms of Active Maintenance and Executive Control (ed. A. Miyake and P. Shah), pp. 102-134. Cambridge University Press: Cambridge.

Fleming, K., Goldberg, T. E., Binks, S., Randolph, C., Gold, J. M. \& Weinberger, D. R. (1997). Visuospatial working memory in patients with schizophrenia. Biological Psychiatry 41, 43-49.

Fletcher, P., McKenna, P. J., Friston, K. J., Frith, C. D. \& Dolan, R. J. (1999). Abnormal cingulate modulation of fronto-temporal connectivity in schizophrenia. Neuroimage 9, 337-342.

Fortin, C. (1999). Short-term memory in time interval production. International Journal of Psychology 34, 308-316.

Fortin, C., Rousseau, R., Bourque, P. \& Kirouac, E. (1993). Time estimation and concurrent nontemporal processing: specific interference from short-term-memory demands. Perceptual Psychophysiology 53, 536-548.

Gibbon, J. (1977). Scalar expectancy theory and Weber's law in animal timing. Psychological Review 84, 278-325.

Gibbon, J., Church, R. M. \& Meck, W. H. (1984). Scalar timing in memory. In Timing and Time Perception. Annals of New York Academy of Sciences 423 (ed. J. Gibbon and L. Allan), pp. 52-77. New York Academy of Sciences: New York.

Gibbon, J., Malapani, C., Dale, C. L. \& Gallistel, C. R. (1997). Towards a neurobiology of temporal cognition: advances and challenges. Current Opinion in Neurobiology 7, 170-184.

Goldberg, T. E., Torrey, E. F., Gold, J. M., Bigelow, L. B., Ragland, R. D., Taylor, E. \& Weinberger, D. R. (1995). Genetic risk for neuropsychological impairment in schizophrenia: a study of monozygotic twins discordant and concordant for the disorder. Schizophrenia Research 17, 77-84.

Goldstone, S., Nurnberg, H. G. \& Lhamon, W. T. (1979). Effects of trifluoperazine, chlorpromazine, and haloperidol upon temporal information processing by schizophrenic patients. Psychopharmacology (Berlin) 65, 119-124.

Harrington, D. L. \& Haaland, K. Y. (1998). Sequencing and timing operations of the basal ganglia. In Timing of Behavior: Neural, Psychological, and Computational Perspectives (ed. D. A. Rosenbaum and C. E. Collyer), pp. 35-61. MIT Press: Cambridge, MA.

Harrington, D. L., Haaland, K. L. \& Hermanowicz, N. (1998a). Temporal processing in the basal ganglia. Neuropsychology 12, $3-12$.

Harrington, D. L., Haaland, K. Y. \& Knight, R. T. (1998b). Cortical networks underlying mechanisms of time perception. Journal of Neuroscience 18, 1085-1095.

Hartocollis, P. (1975). Time and affect in psychopathology. Journal of the American Psychoanalysis Association 23, 383-395.

Holm, S. (1979). A simple sequentially rejective multiple test procedure. Scandinavian Journal of Statistics 6, 65-70. 
Institute for Personality and Ability Testing (1973). Measuring Intelligence with the Culture Fair Test. The Institute for Personality and Ability Testing: Champaign, IL.

Ivry, R. (1993). Cerebellar involvement in the explicit representation of temporal information. In Temporal Information Processing in the Nervous System: Special Reference to Dyslexia and Dysphasia. Annals of the New York Academy of Sciences 682 (ed. P. Tallal, A. M. Galburda, R. R. Llinás and C. Von Euler), pp. 214-230. New York Academy of Sciences: New York.

Ivry, R. (1997). Cerebellar timing systems. International Review of Neurobiology 41, 555-573.

Ivry, R. L. \& Keele, S. W. (1989). Timing functions of the cerebellum. Journal of Cognitive Neurosciences 1, 136-152.

Jastak, S. \& Wilkinson, G. S. (1984). The Wide Range Achievement Test-Revised Administration Manual (Revised Edition). Jastak Assoc. Inc.: Wilmington, DE.

Johnson, J. E. \& Peztel, T. P. (1971) Temporal orientation and time estimation in chronic schizophrenics. Journal of Clinical Psychology 27, 194-196.

Kaufman, A. (1990). Assessing Adolescent and Adult Intelligence. Allyn \& Bacon: Boston.

King, H. E. (1976). Psychomotor correlates of behavior disorder. In Experimental Approaches to Psychopathology (ed. M. L. Kietzman, S. Sutton and J. Zubin), pp. 421-450. Academic Press: New York.

Kremen, W. S., Seidman, L. J., Faraone, S. V., Pepple, J. R., Lyons, M. J. \& Tsuang, M. T. (1996). The '3 Rs' and neuropsychological function in schizophrenia: an empirical test of the matching fallacy. Neuropsychology 10, 22-31.

Lhamon, W. T. \& Goldstone, S. (1956). The time sense: estimation of one second duration by schizophrenic patients. Archives of Neurology and Psychiatry 76, 625-629.

Lhamon, W. T. \& Goldstone, S. (1973). Temporal information processing in schizophrenia. Archives of General Psychiatry 28, $44-51$.

Lhamon, W. T., Goldstone, S. \& Goldfarb, J. L. (1965). The psychopathology of time judgment. In The Psychopathology of Perception (ed. P. H. Hoch and J. Zubin), pp. 164-188. Grune \& Stratton: New York.

McCormack, T., Brown, G. D. A., Maylor, E. A., Darby, R. J. \& Green, D. (1999). Developmental changes in time estimation: comparing childhood and old age. Developmental Psychology 35, $1143-1155$.

McCormack, T., Brown, G. D. A., Maylor, E. A., Richardson, L. B. \& Darby, R. J. (2002). Effects of aging on absolute identification of duration. Psychology and Aging 17, 363-378.

Maricq, A. V. \& Church, R. M. (1983). The differential effects of haloperidol and methamphetamine on time estimation in the rat. Psychopharmacology (Berlin) 79, 10-15.

Maricq, A. V., Roberts, S. \& Church, R. M. (1981). Methamphetamine and time estimation. Journal of Experimental Psychology: Animal Behavior Processes 7, 18-30.

Martin, P. \& Albers, M. (1995). Cerebellum and schizophrenia: a selective review. Schizophrenia Bulletin 21, 241-250.

Meck, W. H. (1986). Affinity for the dopamine D2 receptor predicts neuroleptic potency in decreasing the speed of an internal clock. Pharmacology, Biochemistry and Behavior 25, 1185-1189.

Meck, W. H. (1996). Neuropharmacology of timing and time perception. Cognitive Brain Research 3, 227-242.

Meck, W. H. \& Church, R. M. (1987a). Nutrients that modify the speed of the internal clock and memory storage processes. Behavioral Neuroscience 101, 457-464.

Meck, W. H. \& Church, R. M. (1987b). Cholinergic modulation of the content of temporal memory. Behavioral Neuroscience 101, $457-464$.

Meck, W. H., Church, R. M., Wenk, G. L. \& Olton, D. C. (1987). Nucleus basalis magnocellularis and medial septal area lesions differentially impair temporal memory. Journal of Neuroscience 7 , 3505-3511.

Mimura, M., Kinsbourne, M. \& O'Connor (2000). Time estimation by patients with frontal lesions and by Korsakoff amnesics. Journal of the International Neuropsychological Society 6, 517-528.
Missar, C. D., Gold, J. M. \& Goldberg, T. E. (1994). WAIS-R short forms in chronic schizophrenia. Schizophrenia Research 12, 247-250.

Nichelli, P., Venneri, A., Molinari, M. \& Grafman, J. (1993). Time estimation in different memory disorders. Cognitive Brain Research 1, 87-93.

Nichelli, P., Clark, K., Hollnagel, C. \& Grafman, J. (1995). Duration processing after frontal lobe lesions. Annals of the New York Academy of Sciences 769, 183-190.

Nichelli, P., Alway, D. \& Grafman, J. (1996). Perceptual timing in cerebellar degeneration. Neuropsychologia 34, 863-871.

Nuechterlein, K. H. \& Dawson, M. E. (1984). Information processing and attentional functioning in the development course of schizophrenic disorders. Schizophrenia Bulletin 10, 160-203.

O'Boyle, D. J., Freeman, J. S. \& Cody, F. W. (1996). The accuracy and precision of timing of self-paced, repetitive movements in subjects with Parkinson's disease. Brain 119, 51-70.

Orme, J. E. (1966). Time estimation and the nosology of schizophrenia. British Journal of Psychiatry 112, 37-39.

Park, S., Holzman, P. S. \& Goldman-Rakic, P. S. (1995). Spatial working memory deficits in the relatives of schizophrenic patients. Archives of General Psychiatry 52, 821-828.

Pastor, M. A., Artieda, J., Jahanshahi, M. \& Obeso, J. A. (1992). Performance of repetitive wrist movements in Parkinson's disease. Brain 115, 875-891.

Penney, T. B., Allan, L. G., Meck, W. H. \& Gibbon, J. (1998). In Timing of Behavior: Neural, Psychological and Computational Perspectives (ed. D. A. Rosenbaum and C. E. Collyer), pp. 165-193. MIT Press: Cambridge, MA.

Rammsayer, T. (1989). Is there a common dopaminergic basis of time perception and reaction time? Neuropsychobiology 21, $37-42$.

Rammsayer, T. (1990). Temporal discrimination in schizophrenic and affective disorders: evidence for a dopamine-dependent internal clock. International Journal of Neuroscience 53, 111-120.

Rammsayer, T. H. (1993). On dopaminergic modulation of temporal information processing. Biological Psychology 36, 209-222.

Rammsayer, T. H. (1997). Are there dissociable roles of the mesostriatal and mesolimbocortical dopamine systems on temporal information processing in humans? Neuropsychobiology 35, $36-45$

Rammsayer, T. H. (1999). Neuropharmacological evidence for different timing mechanisms in humans. Quarterly Journal of Experimental Psychology: Comparative and Physiological Psychology 52B, 273-286.

Rammsayer, T. \& Gallhofer, B. (1995). Remoxipride versus haloperidol in healthy volunteers: psychometric performance and subjective tolerance profiles. International Clinical Psychopharmacology 10, 31-37.

Rammsayer, T. H. \& Vogel, W. H. (1992). Pharmacologic properties of the internal clock underlying time perception in humans. Neuropsychobiology 26, 71-80.

Rapp, D. L. \& Robbins, T. W. (1976). The effects of d-amphetamine on temporal discrimination in the rat. Psychopharmacology (Berlin) 51, 91-100.

Seeman, M. V. (1976). Time and schizophrenia. Psychiatry 39 189-195.

Shaw, C. \& Aggleton, J. P. (1994). The ability of amnesic subjects to estimate time intervals. Neuropsychologia 32, 857-873.

Shimamura, A. P., Janowsky, J. S. \& Squire, L. R. (1990). Memory for the temporal order of events in patients with frontal lesions and amnesic patients. Neuropsychologia 28, 803-813.

Shurtleff, D., Raslear, T. G., Genovese, R. F. \& Simmons, L. (1992). Perceptual bisection in rats: the effects of physostigmine, scopolamine and pirenzepine. Physiology and Behavior 51, 381-390.

Stone, M., Gabrieli, J. D., Stebbins, G. T. \& Sullivan, E. V. (1998). Working and strategic memory deficits in schizophrenia. Neuropsychology 12, 278-288.

Stubbs, D. A. \& Thomas, J. R. (1974). Discrimination of stimulus duration and d-amphetamine: a psychophysical analysis. Psychopharmacologia 36, 313-322. 
Tononi, G. \& Edelman, G. M. (2000). Schizophrenia and the mechanisms of conscious integration. Brain Research and Brain Research Reviews 31, 391-400.

Tracy, J. I., Monaco, C., McMichael, H., Tyson, K., Chambliss, C., Christensen, H. L. \& Celenz, M. A. (1998). Information-processing characteristics of explicit time estimation by patients with schizophrenia and normal controls. Perceptual and Motor Skills 86, 515-526.

Tysk, L. (1983a). Time estimation by healthy subjects and schizophrenic patients: a methodological study. Perceptual and Motor Skills 56, 983-988.

Tysk, L. (1983b). Estimation of time and the subclassification of schizophrenic disorders. Perceptual and Motor Skills 57, 911-918.

Tysk, L. (1984). A longitudinal study of time estimation in psychotic disorders. Perceptual and Motor Skills 59, 779-789.

Tysk, L. (1990). Estimation of time by patients with positive and negative schizophrenia. Perceptual and Motor Skills 71, 826.

Volz, H. P., Nenadic, I., Gaser, C., Rammsayer, T., Häger, F. \& Sauer, H. (2001). Time estimation in schizophrenia: an fMRI study at adjusted levels of difficulty. NeuroReport 12, 313-316.

Wahl, O. F. \& Sieg, D. (1980). Time estimation among schizophrenics. Perceptual and Motor Skills 50, 535-541.

Wearden, J. H. (1991). Human performance on an analogue of an interval bisection task. Quarterly Journal of Experimental Psychology 43B, 59-81.

Wearden, J. H. (1992). Temporal generalization in humans. Journal of Experimental Psychology: Animal Behavior Processes 18, 134-144.

Wearden, J. H. (1993). Decisions and memories in human timing. Psychologica Belgica 33, 241-253.

Wearden, J. H. \& Ferrara, A. (1995). Stimulus spacing effects in temporal bisection in humans. Quarterly Journal of Experimental Psychology: Comparative and Physiological Psychology 48B 289-310.

Wearden, J. H. \& Ferrara, A. (1996). Stimulus range effects in temporal bisection by humans. Quarterly Journal of Experimental Psychology: Comparative and Physiological Psychology 49B, $24-44$.

Wearden, J. H. \& Towse, J. N. (1994). Temporal generalization in humans: three further studies. Behavioural Processes 32, 247-264.
Wearden, J. H., Denovan, L., Fakhri, M. \& Haworth, R. (1997a). Scalar timing in temporal generalization in humans with longer stimulus durations. Journal of Experimental Psychology and Animal Behavioral Processes 23, 502-511.

Wearden, J. H., Wearden, A. J. \& Rabbitt, P. M. A. (1997b). Age and IQ effects on stimulus and response timing. Journal of Experimental Psychology: Human Perception and Performance 23 962-979.

Wearden, J. H., Pilkington, R. \& Carter, E. (1999). Subjective lengthening during repeated testing of a simple temporal discrimination. Behavioural Processes 46, 25-38.

Webster, F. R., Goldstone, S. \& Webb, W. W. (1962). Time judgement and schizophrenia: psychophysical method as a relevant contextual factor. Journal of Psychology 54, 159-164.

Wechsler, D. (1981). Wechsler Adult Intelligence Scale-Revised. Psychological Corporation: San Antonio, TX.

Wechsler, D. (1987). Wechsler Memory Scale-Revised. Psychological Corporation: San Antonio, TX.

Weickert, T. W., Goldberg, T. E., Gold, J. M., Bigelow, L. B., Egan, M. F. \& Weinberger, D. R. (2000). Cognitive impairments in patients with schizophrenia displaying preserved and compromised intellect. Archives in General Psychiatry 57, 907-913.

Weinberger, D. R., Berman, K. F. \& Torrey, E. F. (1992). Evidence of dysfunction of a prefrontal-limbic network in schizophrenia: a magnetic resonance imaging and regional cerebral blood flow study of discordant monozygotic twins. American Journal of Psychiatry 149, 890-897.

Wiens, A., Bryan, J. \& Crossen, J. (1993). Estimating WAIS-R FSIQ from the National Adult Reading Test-Revised in normal subjects. Clinical Neuropsychologist 7, 70-84.

Williams, J. M., Medwedeff, C. H. \& Haban, G. (1989). Memory disorders and subjective time estimation. Journal of Clinical and Experimental Neuropsychology 11, 713-723.

Zakay, D. \& Block, R. A. (1996). The role of attention in time estimation processes. In Time, Internal Clocks and Movement (ed. M. A. Pastor and J. Ariteda). pp. 143-164. Elsevier: Amsterdam.

Zakay, D. \& Block, R. A. (1997). Temporal cognition. Current Directions in Psychological Science 6, 12-16. 